\title{
Pearls
}

\section{Pearls: How to Remove a Ceramic Liner From a Well-fixed Acetabular Component}

\author{
Rocco P. Pitto MD, PhD, FRACS
}

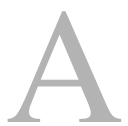

lthough ceramic-on-ceramic bearings enjoy only a small market share of the THAs performed in the United States, they are widely used around the world

Note from the Editor-in-Chief: We are pleased to introduce "Pearls", a new column in Clinical Orthopaedics and Related Research $^{\circledR}$. In this column, distinguished surgeons, scientists, or scholars share surgical or professional tips they use to help surmount important or interesting problems. We welcome reader feedback on all of our columns and articles; please send your commentstoeic@clinorthop.org.

The author certifies that he, or a member of his immediate family, has no funding or commercial associations (eg, consultancies, stock ownership, equity interest, patent/ licensing arrangements, etc.) that might pose a conflict of interest in connection with the submitted article.

All ICMJE Conflict of Interest Forms for authors and Clinical Orthopaedics and Related Research ${ }^{\mathbb{R}}$ editors and board members are on file with the publication and can be viewed on request.

The opinions expressed are those of the writers, and do not reflect the opinion or policy of $C O R R^{\mathbb{R}}$ or The Association of Bone and Joint Surgeons ${ }^{\circledR}$.

R. P. Pitto MD, PhD, FRACS $(\square)$

Department of Orthopaedic Surgery,

Middlemore Hospital, South Auckland

Clinical School, University of Auckland,

70 Symonds Street, Auckland,

New Zealand

e-mail: r.pitto@auckland.ac.nz
[1-6]. While they generally perform well, in some circumstances-particularly in patients presenting with recurrent dislocations-well-fixed modular acetabular components with ceramic liners may require revision.

The dissociation of the ceramic liner from the cup can be difficult, and can result in the unnecessary removal of the cup and liner. To avoid this, the surgeon can perform a simple trick: Using a metallic impactor placed along the external rim of the cup, the surgeon can hit the bearing with a robust hammer blow (Fig. 1). The ceramic liner will dissociate from the internal metal surface. A sharp tool will be necessary to elevate the loosed ceramic liner from the cup margin (Fig. 2).
It should be noted that there are a few modular acetabular components in the marketplace with recessed liner design that may require repeated hammer blows before achieving full dissociation.

When impacting the rim of the metal shell during revision surgery, elastodynamic compressive stress waves are initiated. These compressive stress waves are reflected at physical boundaries (metal and ceramic), transforming into tensile stress waves. When the local tensile dynamic stresses at the interface between the metal and the ceramic exceed the local contact stresses resulting from friction (the taper junction), and adhesion stresses due to contaminations (dried blood,

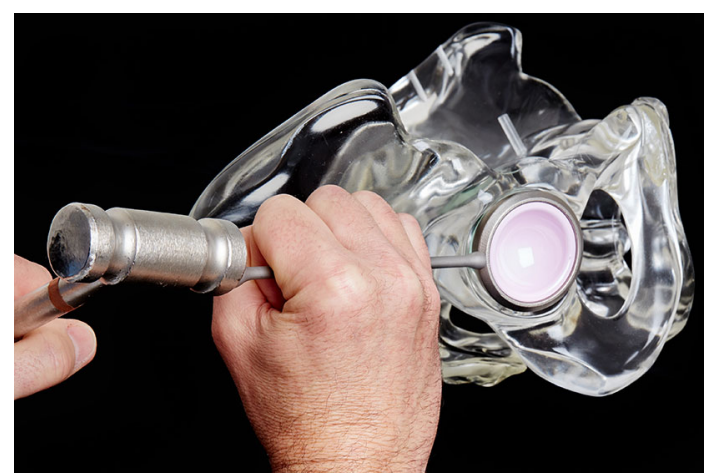

Fig. 1 The impactor is positioned orthogonal to the metal rim of the cup (Published with permission from Rocco P. Pitto MD, PhD, FRACS). 


\section{Pearls}

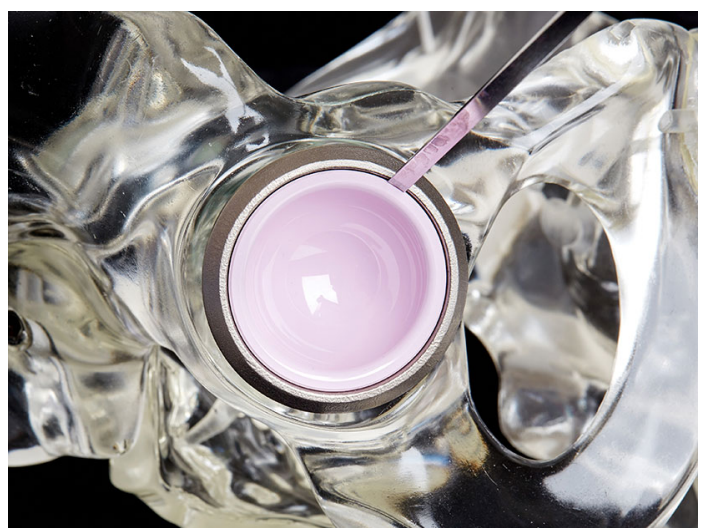

Fig. 2 A small osteotome is used to lift the ceramic liner from the metallic margin of the cup (Published with permission from Rocco P. Pitto MD, PhD, FRACS).

bone fragments), the surgeon will obtain a separation of the interface and loosening of the liner.

If the surgeon replaces the liner, either with ceramic or with polyethylene, double-check that you are using compatible components. The specifications of the taper junction (taper angle, length, surface finish, for example) may differ considerably among manufacturers. The most common taper junction used in THA is the so-called 12/14 Eurotaper or Standard Taper $12 / 14$, but this is only a size designation, not an indicator of compatibility. Using the wrong liner will result in a disaster. Never mix and match!

\section{References}

1. Australian Orthopaedic Association National Joint Replacement Registry. 2015 annual reports. Available at: https://aoanjrr.dmac.adelaide.edu.au/ en. Accessed October 22, 2015.

2. Haute Autorité de Santé. Evaluation of hip replacements [in French]. Available at: http://www.has-sante.fr/ portail/jcms/c_2006405/fr/evaluationdes-protheses-de-hanche. Accessed October 22, 2015.

3. iData Research. U.S. market for large bone \& joint orthopaedic devices. Available at: http://www.idataresearch.com/u-s-market-large-bone-jointorthopedic-devices/. Accessed October 22, 2015.

4. National Joint Registry: 12th Annual report. Available at: http://www.njrcentre.org.uk/njrcentre/NJR12thAnnualReport/tabid/392/Default.aspx. Accessed October 22, 2015.

5. New Zealand Joint Registry. The New Zealand joint registry fifteen year report: January 1999 to December 2013. Available at: http://www.nzoa. org.nz/system/files/NZJR2014Report. pdf. Accessed October 22, 2015.

6. Yano Research Institute Ltd. Market report overview. Available at: http:// www.yanoresearch.com/market_reports/C56107300?class_english_code $=9$. Accessed October 22, 2015. 